\title{
Por una educación política que cualifique la capacidad de las personas para participar como ciudadanas en el campo político
}

\author{
María-Eugenia Villa* \\ Universidad de Antioquia, Colombia \\ https://doi.org/10.15446/frdcp.n20.95714
}

Para que podamos sembrar el pan y para que lo podamos comer...

Una cosa es transportar la piedra para el balcón donde el patriarca, de aquí a unos años, nos bendecirá a todos, otra, y mejor sería, que fuéramos nosotros la bendición y el que bendice, lo mismo que sembrar pan y comerlo.

(Saramago, 2010, p. 305)

La vida de miles de labriegos y la de sus familias fue desperdiciada y malograda durante la construcción del Convento de Mafra (Saramago, 2010). Este monasterio terminó siendo un palacio. Ahora es un sitio turístico conocido bajo la denominación de "Real Obra de Mafra" (Unesco, 2021). Un lugar para ver, no para permanecer. Este sitio de entretenimiento fue

\footnotetext{
* Doctora en Educación por la Universidad Autónoma de Barcelona, España. Profesora de la Universidad de Antioquia, Facultad de Educación (Colombia); integrante del grupo de investigación "Comprender" de la Universidad de Antioquia y del grupo de trabajo académico en educación política "Educar para la Polis" del grupo “Comprender”. Correo electrónico: eugenia.villa@udea.edu.co (iD) https://orcid.org/0000-0003-2189-3373
}

Cómo citar

Villa, M. E. (2021). Por una educación política que cualifique la capacidad de las personas para participar como ciudadanas en el campo político. FORUM. Revista Departamento Ciencia Política, 20, 5-35. https://doi.org/10.15446/frdcp.n20.95714 
construido durante el siglo XVIII por labriegos que han sido olvidados y que estaban sometidos a los designios, que expresaban las ambiciones, del Rey Juan V de Portugal. Sin duda, la construcción de la Real Obra de Mafra, correspondía a la vanidad y a la arrogancia de un rey que debería ser recordado por emplear en su provecho, o beneficio, el oro, los diamantes, el azúcar y el tabaco que extraían y cultivaban las poblaciones de las colonias africanas, americanas y asiáticas del imperio portugués. Igualmente, esta construcción, correspondía a las distinciones que configuran quienes buscan prevalecer y gozar de privilegios, preponderancia y preeminencia con respecto a otras personas. Este tipo de oropeles funcionan como elementos de distinción que aseguran la prevalencia de unas clases dominantes con respecto a otras que permanecen sometidas, subordinadas, dependientes y vulgarizadas (Bourdieu, 1988).

Lo afirmado guarda una razón. No es cierto que las clases sociales se difuminaron entre 1989 y 1991 cuando finalizó el siglo XX (Hobsbawm, 1995). Un siglo en el que muchas poblaciones organizadas lograron que los estados les reconocieran y les hiciesen efectivos muchos derechos (Tilly, 2004). Por esto, en algún momento se creyó que los derechos de las ciudadanías le habían ganado la batalla al ordenamiento capitalista (Marshall, 1997). Sin embargo, esta situación fue difuminada. Cuando el siglo XX finalizó, muchas poblaciones pasaron de gozar de la condición ciudadana a sufrir la condición de súbdita. Desde las dos últimas décadas del siglo XX los privilegios de unas pocas personas vienen ganando el terreno de los derechos de la gran mayoría de las personas. La razón de esta situación tan penosa reside en la penetración de la ideología política neoliberal en los distintos campos de la sociedad global. En adelante, la vida de miles de labriegas, labriegos y la de sus familias se seguirán desperdiciando y malogrando durante la construcción de muchas otras reales obras de Mafra.

En efecto, la penosa construcción de la Real Obra de Mafra no es un asunto del pasado. Mucho menos es el fruto de la imaginación de un eminente escritor (Saramago, 2010). Acaso la construcción de los futuros "estadios de sangre" de Qatar, en los que, de pronto, se disputará la Copa Mundial masculina de la Federación Internacional de Fútbol Asociado (FIFA), de 2022, corresponda a la misma lógica aterradora de la construcción de la Real Obra de Mafra (Linares, 2021). Una lógica que, también, ha malogrado y desperdiciado la vida de más de 6500 trabajadores y las de sus familias a las que, cada día, les hace falta cada uno de ellos. Tal vez la única diferencia, entre la construcción de la Real Obra de Mafra y los futuros "estadios de sangre" de Qatar, sea que los trabajadores de Mafra fueron reclutados, de manera forzada, por cuadrilleros armados que ejercían violencia contra las personas que se les oponían; mientras que los trabajadores de Qatar están llegando a este país huyendo del empobrecimiento y de las otras violencias que sufren en sus lugares de origen (Linares, 2021; Saramago, 2010).

Las y los miles de turistas que visitaban cada año la Real Obra de Mafra (Unesco, 2021) y las y los miles de aficionados a mirar competiciones de fútbol que, posiblemente, asistan 
en el 2022 al mundial masculino de la FIFA tendrían que ver, en cada uno de los oropeles que conforman sus construcciones, la sangrienta huella que deja el fundamento del ordenamiento capitalista: la reificación, la autocracia y la monopolización (Bobbio, 2009; Honneth, 2007; Santos, 2018). En efecto, la Real Obra de Mafra y los futuros "estadios de sangre" de Qatar son obra, en primer lugar, de la reificación de miles de personas y del entorno natural del planeta Tierra. En segundo lugar, de gobiernos autocráticos como el de Juan V de Portugal y el de la familia Al Thani de Qatar (BBC Mundo, 2017). Y, en tercer lugar, de la monopolización, por parte de las elites que apoyaban y apoyan a estos autócratas, de los bienes que creaban las poblaciones que habitaban las colonias del Imperio Portugués del siglo XVIII y que crean las poblaciones que viven bajo el dominio del Estado autocrático de Qatar.

Quizás lo que justifica la configuración de una educación política que forme y socialice a las personas para participar en el campo político sea revertir la reificación, la autocracia y la monopolización imperante en la mayoría de las sociedades del planeta. El fundamento del ordenamiento capitalista malogra y desperdicia miles de vidas. Concretándose en que fuéramos la bendición y quien bendice. Lo que es lo mismo que sembrar el pan y comer ese pan que hemos sembrado (Saramago, 2010). O en ser el bien y quienes desean el bien; generar nuestro bienestar y disfrutar de este bienestar. O que cada quien se colme de bienes y colme de bienes a las y los demás. Porque, finalmente, de lo que se trata es de que cada persona pueda proveerse de los satisfactores de sus necesidades (Max-Neef, Elizalde y Openhayn, 1996). Permitiendo así la dignificación de su condición humana y la contribución a dignificar su condición humana y contribuya a dignificar la condición humana de sus alteridades. De esta forma, cada quien podrá devenir como agente y no como paciente (Sen, 2000); como una persona sujeta de sí misma y no objeto de otra; como una persona autodependiente y no como una persona dependiente. Lo que permite que cada quien se relacione con sus alteridades de manera recíproca o en términos de mutua correspondencia (Mauss, 2009). Respondiendo así a sus alteridades de la misma manera en que ellas han actuado. Porque se consideran iguales en sus diferencias o, mejor, semejantes, similares o congéneres.

La educación de las personas para que sean agentes permite, por tanto, que se desarrollen relaciones de carácter recíproco. Estas relaciones son contrarias a las caritativas y a las filantrópicas que se ejercen entre quienes se consideran desiguales. Por lo que se fundan relaciones entre personas consideradas menores, insignificantes, despreciables, elementales, rudimentarias. Por tanto, susceptibles de ser subalternizadas, subordinadas, sometidas y dominadas. Lo que las hace dependientes y sujetas de la voluntad de otras personas que fungen como mayores, importantes, respetables, primordiales, educadas y cultas. Por lo que logran gozar de los atributos brindados para ocupar los lugares de las sociedades desde los que se puede ejercer dominación. De esta forma, llegan a ser las personas que conforman la 
clase llamada como "gente de alta sociedad", "gente bien" cuyas poses y prácticas hacen que sean distinguidas de la "gente de la baja sociedad"; de la gente sospechosa de hacer el mal. "La gente bien" ha construido este imaginario para defender su prevalencia en los campos político y económico. Esta prevalencia se asegura de dos formas: mediante el ejercicio de la disuasión y la persuasión y mediante el ejercicio de la coacción que pueden llevar hasta el grado de la violencia. En otras palabras, mediante el ejercicio de dos poderes sociales: el ideológico y el coactivo (Villa, 2021a).

Una de las maneras en las que se expresa ese ejercicio es asegurarse que las personas que son sujetas de su prevalencia y víctimas de sus privilegios, de su preponderancia y de su preeminencia transporten la piedra con la que se construirá el balcón del Convento de Mafra desde el que unos años más tarde el patriarca, con un gesto mínimo, les hará saber que no son personas sujetas de derechos. Si no que, por el contrario, son personas menores, insignificantes, despreciables, elementales y rudimentarias como aquel "labriego de tanta edad que ya no lo quisieron" y que después de gritar "subido a una cerca que es el púlpito de los rústicos, Oh gloria de mandar, oh vana codicia, oh rey infame, oh patria sin justicia" recibió del cuadrillero, que había reclutado para trabajos forzados a su hijo, un golpe en la cabeza con el que lo dejaron tirado en el suelo dado por muerto (Saramago, 2010, p. 362).

Quizá para evitar que sigan sucediendo estas situaciones dolorosas sea fundamental una educación política que forme y socialice a las personas para participar en el campo político. Quizá para que unas personas dejen de ser consideradas menores, insignificantes, despreciables, elementales y rudimentarias, al tiempo que otras son consideradas mayores, importantes, respetables, primordiales, educadas y cultas sea trascendente una educación política que forme y socialice a las personas para participar en el campo político. Quizá para que todas las personas puedan gozar de los derechos que son inherentes a la condición humana sea valiosa una educación política que forme y socialice a las personas para participar en el campo político. Quizá para que todas y todos puedan ser la bendición y quien bendice -que es lo mismo que poder sembrar el pan y poder comerlo- sea vital una educación política que forme y socialice a las personas para participar en el campo político.

\section{Un concepto de educación política}

La educación política puede definirse como un proceso de socialización y de formación que permite que las personas se movilicen o que participen en el campo político. En donde se entiende que los procesos de movilización política son la antípoda de los procesos de participación política (Sani, 2000). Una de las razones por las que se puede hacer esta afirmación es que la movilización política se logra mediante el adoctrinamiento. 
Lo que consiste en inculcar a otra u otras personas unos sentidos determinados con un gran empeño, con la finalidad de fortalecer el ordenamiento autocrático. Por su parte, la participación política se logra mediante procesos de politización. Estos consisten en enseñar con compromiso a otra u otras personas una diversidad de sentidos con la finalidad de fortalecer el ordenamiento democrático (Žižek, 2011).

En el campo de la educación política para la movilización en el campo político se pueden identificar dos formas de realización: la primera corresponde a la instrucción cívica y la segunda a la educación cívica. Ambas formas conducen a la formación de súbditos de un determinado ordenamiento político. Con la instrucción cívica se pretende la adhesión a una ideología política y, a veces, a una agrupación social. La adhesión a una ideología política típicamente se refiere a algún tipo de nacionalismo. La adhesión a una agrupación social generalmente se refiere a algún estado nación. Por su parte con la educación cívica se busca alcanzar tres finalidades: la primera se refiere a la movilización para la elección de alguna o algunas de las personas que conforman el gobierno de una determinada sociedad; la segunda se refiere al cumplimiento de los deberes que imperan en un preciso ordenamiento político y la tercera hace referencia a las maneras de relacionarse, de un modo sumiso, con quienes conforman el gobierno de una específica sociedad.

En el campo de la educación política para la participación en el campo político se pueden identificar dos formas de politización. La primera es la educación para el ejercicio de la ciudadanía. Esta educación se realiza cuando se concibe que la condición ciudadana se ejerce de manera homogénea. La segunda es la educación para el ejercicio de las ciudadanías. Esta educación se realiza cuando se concibe que la condición ciudadana se ejerce de manera heterogénea ${ }^{1}$. Ya sea que se desarrolle de una manera o de la otra, la educación política para la participación en el campo político implica que cada persona llegue a "ser parte" del campo político y con ello que devenga en contener en sí el proceso y luego en ser el proceso político (Wilches-Chaux, 1993, p. 5). Lo que contribuye a la democratización del campo político. Esto se puede afirmar si, con Žižek (2011), se entiende que todo proceso de politización de las poblaciones de un determinado contexto social, conlleva, la democratización de esta sociedad.

Por lo escrito, la educación política debería cualificar las capacidades de las personas para participar como ciudadanas en el campo político. A partir de este concepto en los apartes que siguen se abordará, una finalidad, una justificación, unos contextos, unos contenidos y un método para la realización de un proceso de educación política.

1. En esta parte debo expresar mis agradecimientos a los profesores Francisco Javier Rico Arteaga y Mauricio Berrio Arismendy por los aportes que, en torno a la heterogeneidad del ejercicio de la condición ciudadana, han realizado en el grupo de trabajo académico en educación política "Educar para la Polis" del grupo "Comprender". 


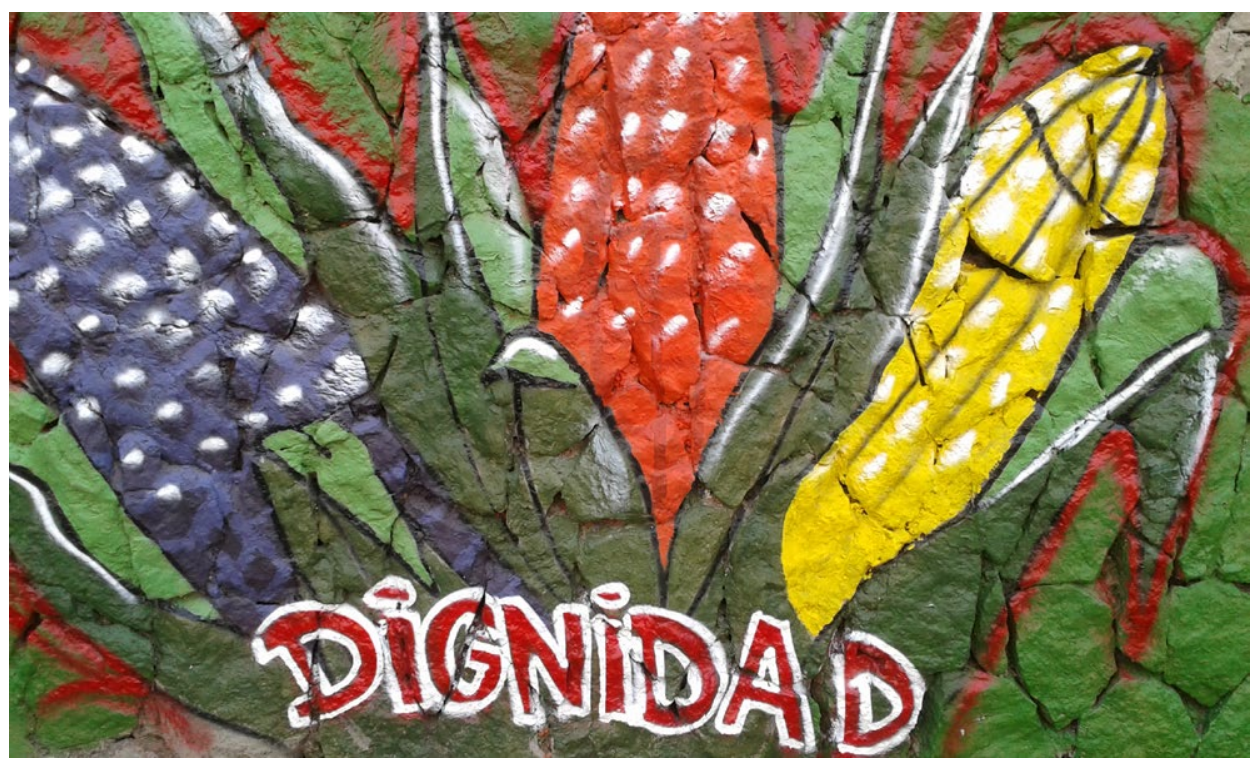

Fotografía de María-Eugenia Villa. Muro de las dignidades 2015, Universidad de Antioquia.

\section{Una finalidad, una justificación y unos contextos para la educación política}

Desde el punto de vista deontológico, una educación política para la participación en el campo político debería tener como finalidad construir sociedades en las que se concrete el reconocimiento (Honneth, 2007), la democracia (Bobbio, 2009) y la redistribución (Santos, 2018). Estos ideales se muestran deseables por varias razones. La primera es que el reconocimiento permite el establecimiento de relaciones recíprocas (Mauss, 2009) y la termorregulación ambiental (Calderón et al., 1995) permite habitar el planeta Tierra de manera tal que la humanidad no provoque una nueva extinción masiva de las especies que lo pueblan. La segunda razón por la que estos ideales son deseables consiste en que la democracia permite que todas las personas que hacen parte de un determinado ordenamiento político puedan ser sujetas de los derechos que son inherentes a toda la humanidad. Finalmente, la redistribución es deseable en tanto permite el disfrute general de los bienes que, en conjunto y de manera cotidiana, crean, en sus entornos naturales, las personas que hacen parte de una sociedad (Dussel, 2013). Lo que cobra validez si se entiende que cada una de las briznas que componen los seres animados y los inanimados son el fruto del trabajo de todo el universo desde los tiempos en los que no existía el tiempo. Escrito de otro modo, desde el punto de vista deontológico, una educación política para la participación en el campo político debería tener como finalidad 
diluir las situaciones que nos han llevado a sufrir la tragedia que acongoja en este momento a toda la humanidad: la pandemia de la Covid-19. Estas situaciones consisten en la reificación de las personas y de la naturaleza; la autocratización de la mayoría de las sociedades del planeta y la monopolización por parte de pocas personas de los bienes que, colectiva y cotidianamente, crean, en sus entornos naturales, las personas que conforman la sociedad global.

De manera más precisa, en la contemporaneidad se torna urgente cualificar y ampliar las prácticas que conlleva la educación política para participar en el campo político. Esto se justifica por la regresión de la interculturalidad que permite la existencia humana; por el avance de la entropía que destroza los entornos naturales; por el retroceso de los procesos de democratización de las sociedades y, a nivel planetario, el enriquecimiento de unas pocas personas merced al empobrecimiento de la mayoría de las personas. Una situación que torna obscena o impúdica la convivencia global. Pues no puede ser más escabroso y sórdido que la miseria material de muchas personas sostenga la miseria moral de unas pocas. Por tanto, más precisamente se requiere una educación política que forme y socialice a las personas para participar en el campo político. Esta educación, en términos de Santos (2009), nos concedería unos conocimientos y unos saberes prudentes para construir una vida decorosa, decente.

Finalmente, una educación política para la participación política se puede llevar a cabo en contextos educativos escolarizados y no escolarizados. Pero, sobre todo, esta educación política se realiza en el ámbito de procesos colectivos. Unos procesos que implican la organización de las personas en colectividades que, eventualmente, pueden institucionalizarse. Esto puede ser así, en razón de la formalización entrañada por el campo político; permitiendo la perdurabilidad de las organizaciones que las personas conforman en las sociedades y que ayuda a distinguir la política de lo político, lo instituido de lo instituyente, lo transformable de lo transformador (Mouffe, 2017). Una formalización siempre deseable. Pues, como lo ha escrito Lechner, es en el ámbito de la formalización en el que se expresa la subjetividad. Esa fuerza que crea calas en la política desde las posibilidades de lo político. Aserto que se origina en la especificación del campo político como el espacio de la formalización y de la expresión subjetiva (Lechner, 1981). Una paradoja que no es extraña a las divergencias tan caras a la condición humana.

Por lo escrito, es trascendente que en los contextos educativos escolarizados y no escolarizados el profesorado promueva los procesos organizativos del estudiantado (Entwistle, 1980). Esto ha de suceder tanto en el aula de clase como en los distintos espacios escolares. Y ha de realizarse para el desarrollo de muchas de las actividades y tareas cotidianas de la escuela. La razón de esto es doble: la primera tiene que ver con una idea planteada por el profesor Isabelino Siede en la entrevista que concedió para este monográfico. Esta idea estriba en que la escuela es el primer espacio público al que acceden las niñas 
y los niños. Antes de la escuela su vida se concentra en los ámbitos íntimo y privado. La segunda razón por la que el profesorado debe estimular los procesos organizativos del estudiantado consiste en que, estos procesos, conllevan a la participación del estudiantado. Lo que le permite a cada estudiante aprender a participar. Como lo ha escrito Entwistle (1980), la participación no se aprende a través del método de la simulación.

Este método puede servir para aprender, por ejemplo, las funciones que deben cumplir los distintos agentes y pacientes que hacen parte de un determinado contexto social (Sen, 2000). De esta manera, la participación escolar le permite a cada estudiante, en primer término, desarrollar las capacidades que le permitirán participar en otros ámbitos. En segundo término, cualificar sus otras capacidades. Esto lo han de hacer cooperando con quienes son sus coetáneas y coetáneos, así como negociando con quienes han devenido a la condición de adultez u ocupan los distintos lugares desde los que se ejerce el gobierno de lo social (Villa, 2011). Y, en tercer término, la participación escolar le brinda a cada estudiante la posibilidad de satisfacer la necesidad de participación y, además, sus otras necesidades humanas las cuales son: subsistencia, protección, afecto, entendimiento, ocio, creación, identidad y libertad (Max-Neef, Elizalde y Openhayn, 1996). Finalmente, ha de escribirse que desde lo deontológico la participación ha de aprenderse en la escuela a partir de la práctica individual y colectiva del reconocimiento, de la democracia y de la redistribución.

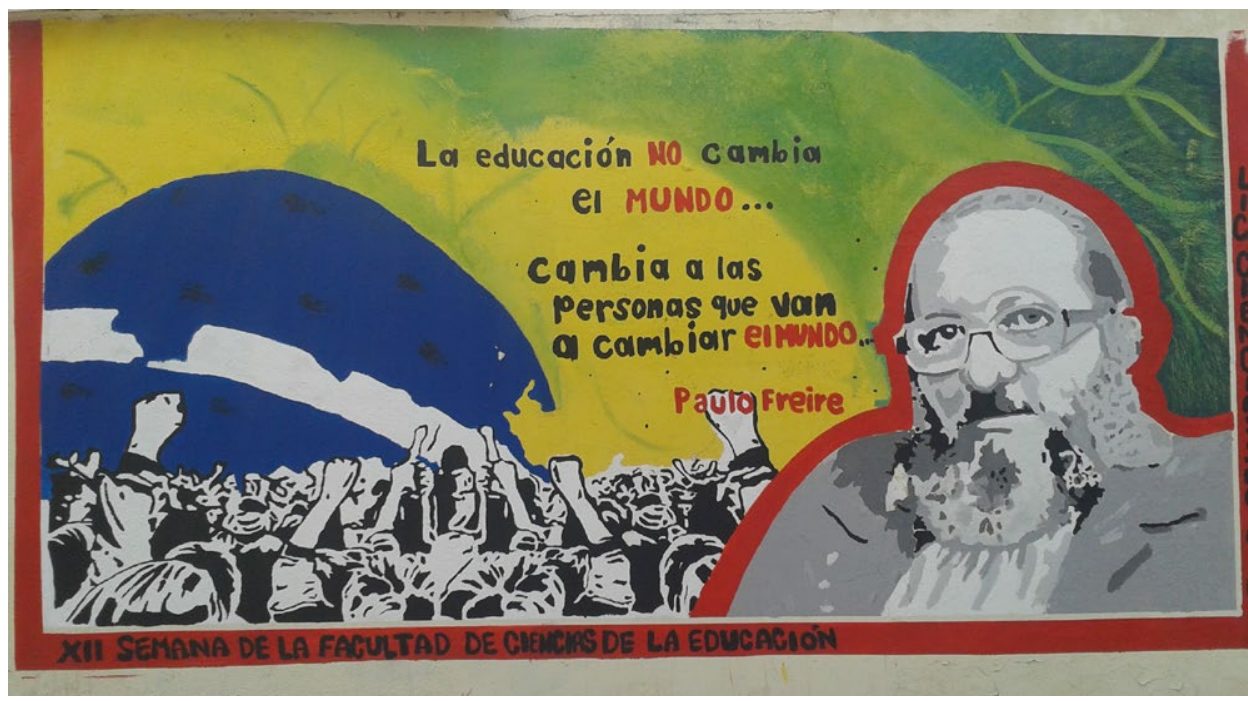

Fotografía de María-Eugenia Villa. Para leer las sociedades y para reescribir las sociedades 2014, Universidad del Tolima. 


\section{Unos contenidos y un método para la educación política}

Una educación política para la participación en el campo político puede desarrollarse desde diversas perspectivas. Estas deberían iniciarse con la descriptiva, proseguir con la deontológica y culminar con las prescriptivas y proscriptivas que han de configurarse para la convivencia pacífica (Villa, 2015a). Tanto las prescripciones como las proscripciones corresponden a la formalización a la que tiende el campo político (Lechner, 1981). Unas y otras deberían contribuir a la convivencia pacífica para la dignificación de la condición humana. La convivencia pacífica, a su vez, se puede fundamentar en la teoría de la noviolencia (López-Martínez, 2004) y en sus distintas concreciones. Una de estas es la del deber que tienen todas las personas de desobedecer las prescripciones y proscripciones que instituyen los Estados cuando las consideran injustas o inequitativas (Thoreau, 2005).

Para la concreción de estas perspectivas, el profesorado debería llevar a cabo tres acciones. La primera es la de construir los contenidos de los procesos educativos en el contexto de grupos de trabajo académico docente. Lo que afina la condición intelectual que debe caracterizar al profesorado (Villa, 2015b). La segunda acción que debe realizar el profesorado debería ser la de acudir al campo sociohumanístico del conocimiento científico para construir estos contenidos. En especial a los campos de la historia, la geografía, los estudios culturales, la ciencia política, la filosofía política, las ciencias jurídicas, la economía, la sociología, la filosofía, la literatura, el cine, la fotografía, las artes plásticas, las artes representativas... Igualmente, como lo sostienen Henao y Palacio (2019), cada día se torna más inaplazable acudir al campo de las ciencias naturales para la construcción de los conocimientos escolares. Además, para la sobrevivencia de la especie humana, al día de hoy, igualmente se debería también acudir a los campos de otras formas de construir sentidos para construir los conocimientos escolares. Estos campos son el de los saberes ancestrales, el de los saberes afrodiaspóricos y los de las organizaciones campesinas, rurales y urbanas. Saberes que permiten ir más allá de las resistencias para avanzar a las reexistencias (Botero, 2014; Santos, 2009). O, lo que es lo mismo, pasar de la rebeldía a la revolución (Freire, 2009; Fromm, 2008). Un paso que entraña desatarse de los entramados del carácter autoritario o sadomasoquista para acceder a los campos en los que se puede ejercer el carácter libertario. Un carácter que implica que cada quien pueda disponer de la capacidad, la posibilidad o el poder de responder por sí misma o por sí mismo (2021a). Finalmente, desde el punto de fuga de las reexistencias, el profesorado debería construir el conocimiento escolar desde las metáforas topológicas del sur del sur y del sur del norte. La razón de esto es que existe un norte del norte y un norte del sur. Unos nortes que generalmente permanecen 
aliados y que, frecuentemente, provocan discordias, hostilidades, enemistades y pugnas entre quienes nos ubicamos en el sur. Con esto evitan que entre las sociedades del sur se establezcan relaciones de concordia, mancomunidad, amistad y armonía que ayuden a dignificar la condición humana.

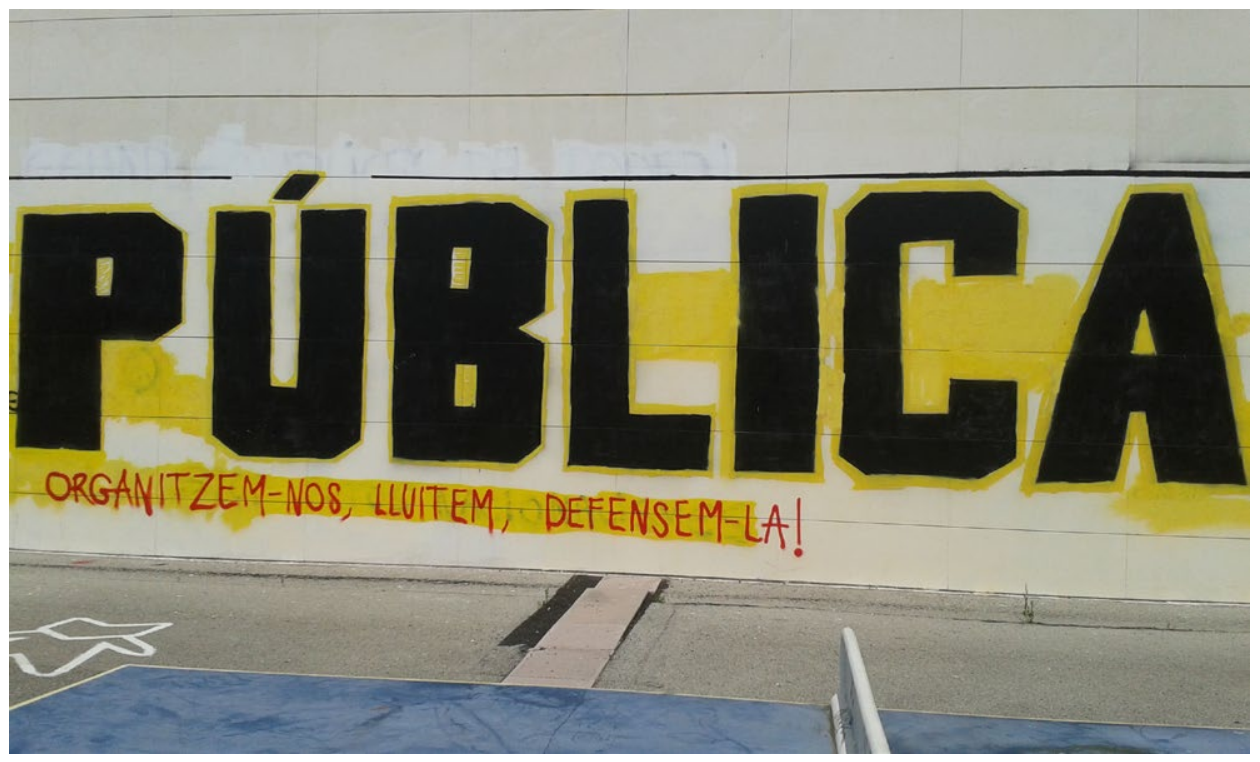

Fotografía de María-Eugenia Villa. Pública por siempre 2015, Universidad Autónoma de Barcelona.

Con todo, la construcción de conocimientos escolares en el contexto de grupos de trabajo académico docente, acudiendo a los campos de diferentes formas de saber y de conocer, así como desde la metáfora topológica del sur ayuda a colmar dos ideales caros a la dignificación de la condición humana. Uno es el que se "establezcan alianzas" entre las luchas de las sociedades del sur (Thiong'o, 2017, p. 111). El otro es el de contribuir a la construcción de una sociedad planetaria que supere el eurocentrismo. Lo que permitiría, por tanto, pasar del unicentrismo al pluricentrismo. De esta forma, la nueva sociedad planetaria tendría múltiples centros que se deberían considerar entre sí como legítimos. Este desplazamiento del centro sobre el que ha insistido Thiong'o (2017), contribuye, en mucho, a construir relaciones humanas en las que predomine el reconocimiento que le abre paso a la democracia que posibilita la redistribución. 
Para cerrar esta parte, un método para la realización de procesos de educación política para la participación política puede desarrollarse a partir de procesos de deliberación en torno a situaciones reales. En consecuencia, estas situaciones, no deben ser simuladas (Entwistle, 1980). Los procesos de deliberación han de tener como finalidad la construcción de resoluciones o de decisiones mediante consensos o acuerdos. Lo que implica que se debe prescindir del mecanismo de la votación. Esto porque una votación, de suyo, excluye el consenso en la medida en que una mayoría predomina sobre una minoría. La deliberación se ha de fundamentar en la construcción de argumentos y de contraargumentos que el profesorado, agente central de los procesos de educación política, debe enseñar a construir a cada estudiante. Dado que la función que tiene cada profesor y profesora en los procesos de educación política para la participación en el campo político es imprescindible. No se puede imaginar la enseñanza de la participación centrada en el aprendizaje. Es un proceso que implica enseñar y aprender en contextos de construcción colectiva de conocimientos y de saberes, así como de desarrollo de capacidades.

Para que el profesorado pueda cumplir con su función de enseñanza de la participación en el campo político bien puede servirse de un método de construcción de experiencias que está en elaboración. Este método se ha denominado DAR (Villa, 2021 b) y se fundamenta en el concepto de "experiencia" sobre el que ha profundizado Larrosa (2006). Este método se denominó DAR en tanto implica la descripción o especificación; el análisis o crítica y la reflexión o valoración (Villa, 2021b) que se han de desarrollar por parte de cada estudiante a partir de una situación real y con la orientación de una profesora o de un profesor. Las situaciones en las que se centra el método bien pueden referirse a las escalas de interacción local, regional o global y ser del presente o del pasado. Con respecto a esto puede recomendarse que estas situaciones que se han de describir, analizar y ser objeto de reflexión deberían corresponder al pasado y situarse en una escala de interacción global. Lo que permite al estudiantado mirar lo otro para poder ver lo propio tal y como lo ha recomendado Pagès (1997). Las capacidades que se intentan desarrollar mediante el método DAR - descripción, análisis y reflexión- sin duda son esenciales en todo proceso de educación política que se oriente a la formación y a la socialización del estudiantado para participar en el campo político. Una educación que le permite a las personas ser la bendición y quien bendice o, lo que es lo mismo, sembrar el pan y poderlo comer (Saramago, 2010). 


\section{Un conjunto de aportes al campo de la educación política}

Con el fin de aportar en el campo de la educación política este monográfico de la revista FORUM contiene siete artículos, una reseña, una entrevista y un artículo de reflexión mediante el que se brinda un reconocimiento a un educador político de varias generaciones de profesoras y de profesores iberoamericanos: el profesor Joan Pagès i Blanch. Un maestro que nos dejó de manera inesperada en un momento en el que más podía colmarnos con todas las formas en las que tornaba práctico el valor de la reciprocidad. Este artículo ha sido escrito por el profesor Antoni Santisteban, otro educador político, que viene acrecentando la herencia intelectual de un maestro de maestros como lo fue el profesor Pagès.

Vale, por tanto, declarar que este monográfico está dedicado a la memoria del profesor Pagès e, igualmente, a las víctimas de la violencia que el gobierno del Estado colombiano ha ejercido en contra de las poblaciones colombianas desde el 28 de abril de 2021. El día en que se inició un "Paro Nacional" en contra del gobierno del presidente Iván Duque. Un paro que ha sido causado por el empobrecimiento de la mayoría de la población colombiana. Un empobrecimiento que, en Colombia, como en el resto de sociedades del planeta, ha sido ocasionado por la imposición de la ideología política neoliberal como orientadora de las políticas que prescriben y proscriben las acciones de los estados. La dedicatoria de este monográfico a las víctimas de este nuevo momento de ejercicio de la violencia militar y paramilitar en Colombia se realiza por una convicción. La de que el profesor Pagès también estaría lamentando que tantas personas sufrieran una infinidad de daños por su reivindicación, como ciudadanas y ciudadanos, de los derechos de las poblaciones colombianas ${ }^{2}$. Unos derechos que suelen ser arrebatados por quienes

\footnotetext{
2. Al cierre de la escritura de esta presentación -19 de mayo de 2021- las organizaciones no gubernamentales Indepaz y Temblores han informado que, entre el 28 de abril y el 18 de mayo de 2021, han logrado documentar 2387 casos de violencia ejercida por parte de las organizaciones militares del Estado colombiano en contra de las poblaciones colombianas. Se puede agregar que en las ciudades de Pereira, Cali y Medellín la población ha registrado la presencia de personas civiles armadas. Con lo que se presume que las organizaciones militares del Estado colombiano continúan recibiendo apoyo de organizaciones paramilitares. Estos 2387 casos de violencia se han registrado durante distintas actividades que han hecho parte del Paro Nacional contra las acciones de gobierno neoliberales del presidente Iván Duque. Con respecto a estos casos de violencia Indepaz y Temblores lograron precisar que 51 personas fueron asesinadas. De estas, 43 fueron presuntamente asesinadas por integrantes de las organizaciones militares del Estado colombiano; la mayoría fueron asesinadas en los departamentos de Cauca y de Valle del Cauca - 35 personas; 4 eran menores de edad y 15 tenían entre 18 y 24 años-. Con lo que se puede afirmar que la violencia ejercida por el Estado colombiano en contra de las poblaciones colombianas ha sido más mortífera en el suroccidente colombiano y que se ha concentrado en la niñez y en la juventud. Las dos organizaciones no gubernamentales también han documentado que 18 personas son víctimas de violencia sexual; 5 son víctimas de violencia basada en género; 33 son víctimas de heridas oculares; 1139 son víctimas de detenciones arbitrarias y 384 son víctimas de violencia física. A estos
} 
le imponen el neoliberalismo a las sociedades mediante el ejercicio de la violencia militar - como en el caso de Chile- o paramilitar - como en el caso de Colombia-.

daños a las poblaciones colombianas se le suma que, para el 10 de mayo, ambas organizaciones denunciaron más de 500 casos de personas dadas por desaparecidas después de haber sido detenidas en el marco de las protestas concernientes al Paro Nacional e informaron que 2 de ellas fueron encontradas muertas el 7 de mayo. Finalmente, estas dos organizaciones, denunciaron que han registrado 146 casos de disparos con armas de fuego y 472 intervenciones violentas en el marco de protestas pacíficas que se han realizado en el marco del Paro Nacional. En los informes de las dos organizaciones se consignan cuatro características de la violencia ejercida por parte del Estado colombiano en contra de las poblaciones colombianas. La primera es que la mayoría de estos hechos victimizantes se han cometido en las horas de la noche. La segunda es que se ha denunciado que, durante el desarrollo de estos hechos, se han presentado cortes en los servicios eléctricos residenciales y del alumbrado público. También se ha denunciado la interrupción del servicio de internet. Esto ha resultado particularmente grave dado que muchas personas se han salvado de ser victimizadas o han denunciado hechos de victimización a través de las redes sociales en línea y durante transmisiones en directo. La tercera característica de esta violencia es el uso de armas químicas como lo son los gases lacrimógenos. Estas armas se han usado, además, en lugares residenciales y a altas horas de la noche. Con lo que se ha puesto en peligro a un número incontable de familias de las que hacen parte ancianas, ancianos, niños, niñas y bebés. Muchas familias han quedado atrapadas en sus casas a merced de las armas químicas. Esto a causa de que se han registrado policías disparando armamentos letales en las calles de los barrios mientras transitaban a pie o a bordo de las motocicletas, de las tanquetas o de los demás vehículos de los que se sirve la policía colombiana. La última característica es que, igualmente, en lugares residenciales se han usado, en contra de las poblaciones colombianas, unos lanzadores de múltiples proyectiles denominados "Venom". Estas armas se han disparado desde tanquetas y desde el suelo. Lo que al parecer le da más letalidad al uso de este instrumento de ataque. Si se tiene en cuenta que cada una de estas armas tiene un costo cercano a los 400 millones de pesos, se puede colegir que el gobierno del presidente Duque le brinda más importancia al ejercicio de la violencia contra las poblaciones colombianas que a sus obligaciones de reconocer y hacer efectivos los derechos de las distintas poblaciones que habitan en Colombia. Es de anotar que Indepaz ha denunciado la continuidad de la violencia que, en Colombia, siempre se ha ejercido contra los líderes y las lideresas políticas y contra las personas que han firmado los distintos acuerdos de paz. Unos acuerdos que el Estado colombiano ha suscrito con diferentes organizaciones subversivas armadas. En efecto, esta organización ha informado que entre el 28 de abril y el 18 de mayo, se han cometido 9 asesinatos de personas que lideran procesos sociales y que defienden los Derechos Humanos. Igualmente, registró el asesinato de dos personas firmantes del Acuerdo de Paz entre el Estado colombiano y la Jefatura de las Fuerzas Armadas Revolucionarias de Colombia (FARC-EP). De esta forma, a las víctimas que cotidianamente se le venían sumando a la violencia que caracteriza el campo político colombiano, desde el 28 de abril, se le están adicionando las víctimas de la violencia que el Estado colombiano está ejerciendo en contra de las poblaciones colombianas. Esta situación tiende a agravarse. La razón de esto es que el 17 de mayo el presidente Duque anunció que desplegará la capacidad máxima de las organizaciones militares del Estado colombiano en toda Colombia. Hecho este anuncio se teme que aumente el riesgo de victimización de las personas que están participando en las diversas actividades del Paro Nacional; de las personas que le brindan auxilio a las víctimas que participan en estas actividades y de las personas que viven o que transitan por los lugares en los que se están realizando las actividades concernientes al Paro Nacional o por sus lugares aledaños (Human Rights Watch dice que tanquetas de la Policía con proyectiles son "peligrosas" e "indiscriminadas", 2021; Indepaz, 2021; Temblores ONG, 2021a, 2021b). 
Como se ha anotado, los artículos que contiene el monográfico dan cuenta de procesos de investigación en el campo de la educación política. Estos fueron remitidos desde Europa y Latinoamérica. Con respecto a los que llegaron de Europa dos corresponden a España y uno al Reino Unido. Con relación a los que fueron recibidos de Latinoamérica uno proviene de Argentina y tres de Colombia. A continuación, se presentan algunas de las características de las investigaciones de las que dan cuenta.

La perspectiva desde la que se abordó la educación política fue en su mayoría la de la formación ciudadana - tres artículos-. De estos, dos se centran en la formación ciudadana en general y uno en la formación ciudadana para la democracia. Los otros cuatro artículos se centran en perspectivas distintas: la configuración de la subjetividad política; el desarrollo de competencias en el campo de la educación para la ciudadanía democrática; la educación política para una democracia radical y la formación para la participación ciudadana.

Los ámbitos educativos en los que se realizaron las investigaciones fueron en su gran mayoría en la educación escolarizada. Esto porque seis investigaciones se hicieron en este ámbito y una se realizó en el de la educación no escolarizada. En la educación escolarizada dos investigaciones se realizaron con estudiantes de primaria y secundaria. Las otras fueron con estudiantes de la educación superior, estudiantes y profesorado de la educación superior, profesorado y estudiantes de la educación secundaria y profesores de la educación media. La investigación que se realizó en el ámbito de la educación no escolarizada se realizó con personas jóvenes y adultas.

Los lugares en los que se realizaron estas investigaciones fueron Latinoamérica y Europa. En Latinoamérica fueron realizadas tres investigaciones: una en Colombia, una en Argentina y otra en Chile. En Europa se realizaron dos investigaciones: una en Andorra y otra compila resultados de varias investigaciones realizadas en España.

Los métodos que se utilizaron para la realización de las investigaciones fueron, en su mayoría, el estudio de caso. Este método se usó en tres investigaciones. Una de estas se sirvió de la teoría fundamentada para el análisis de datos. Dos investigaciones se basaron en la revisión documental; una en la investigación acción y el proceso en el ámbito educativo no escolarizado fue estudiado mediante una sistematización de esta experiencia. Para esta sistematización se pidió a las y los participantes que escribieran relatos con la intención que, desde lo subjetivo, dieran cuenta de la experiencia construida a lo largo de su proceso de formación. A continuación, se describirá el contenido de los siete artículos que contiene este monográfico sobre educación política. 


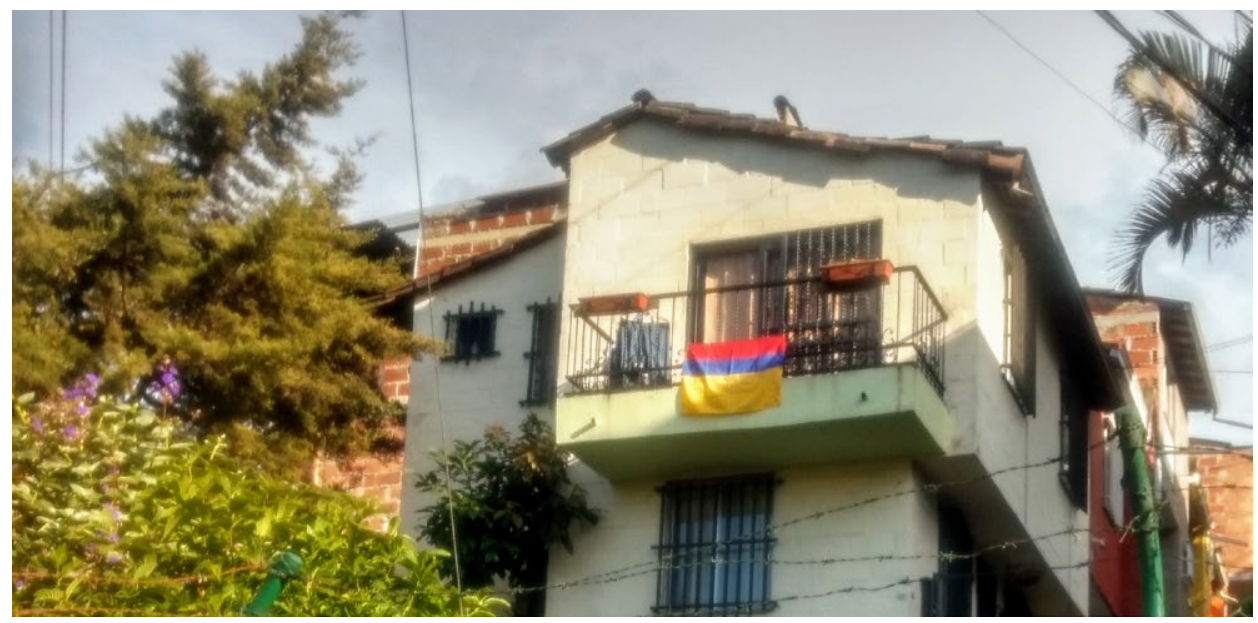

Fotografía de María-Eugenia Villa. SOS Colombia 2021, en una esquina de Medellín.

\section{Una descripción de los aportes al campo de la educación política contenidos en este monográfico}

A continuación, se describen los siete artículos que se seleccionaron para hacer parte de este monográfico. La descripción de cada uno consta de dos partes. En la primera se presentan las características de la investigación de la que el artículo busca dar cuenta. En la segunda se precisan los aportes de estas investigaciones al campo de la educación política. Con relación a las características de las investigaciones se específica su lugar de realización; la perspectiva desde la que se aborda la educación política; la condición social de las personas que participaron; el objetivo de la investigación y el método utilizado para realizarla. En cuanto a los aportes de estas investigaciones al campo de la educación política se describe su finalidad enunciada; los contenidos propicios para realizarla y los métodos a los que puede recurrir el profesorado para la educación política del estudiantado. Al final de la descripción de cada artículo se consignan las perspectivas de investigación que deja cada una de las investigaciones de las que busca dar cuenta cada artículo.

Los primeros seis artículos corresponden al ámbito de la educación escolarizada. El primero de estos fue escrito por las profesoras María Inés Jorquera y Laura Radetich. Se titula "Educación política en Argentina. Participación juvenil, política educativa, enseñanza y contextos”. Como lo indica el título, la investigación se refiere a Argentina. La perspectiva desde la que se aborda la educación política corresponde a la formación ciudadana. La investigación se refiere al estudiantado de la educación primaria y secundaria. El objetivo de la investigación fue el de interpretar las transiciones de la 
educación política en Argentina. Esta interpretación se centró en los cambios históricos, en especial, en los políticos. La investigación permitió entender que estos cambios fueron provocados por las dinámicas de la participación política de las personas jóvenes y los cambios en las políticas referidas a la educación y a las juventudes. El artículo postula que las transiciones de la educación política en Argentina permitieron construir un modelo de educación política basado en el ejercicio pleno e integral de la actividad política por parte de las y los jóvenes a partir de la perspectiva de los derechos. El método que se utilizó para la realización de la investigación fue el de la revisión documental.

Desde la perspectiva de la formación ciudadana en el artículo se propone que la finalidad de la educación política en la Argentina contemporánea se compone de dos aspectos. El primero consiste en el fortalecimiento de la identidad nacional, de la democracia, de la construcción de memoria histórica, de la defensa de los Derechos Humanos, de la integración latinoamericana, de la diversidad cultural y de los derechos de los pueblos originarios. El segundo aspecto se orienta a promover los valores de la igualdad y la solidaridad; así como el respeto entre los sexos y la lucha en contra de la discriminación de la mujer. Con lo que, en suma, la finalidad de la educación política estriba en formar al estudiantado de la educación escolarizada para ejercer plena e integralmente la ciudadanía, trabajar y continuar con sus estudios. En cuanto a los contenidos, estos deben ser construidos a partir de las teorías y de los conocimientos que han sido configurados en el campo de las ciencias sociales. Sus métodos de enseñanza se fundamentan en estrategias críticas ancladas a la realidad social del estudiantado y en el ejercicio pleno e integral de la ciudadanía. Estos fundamentos se han configurado en el contexto de un estado de derecho que reconoce la legitimidad del protagonismo de las niñas, de los niños y de las y los jóvenes.

Después del "Cacerolazo" de 2001 las poblaciones argentinas cuestionaron la eficacia que la ideología política neoliberal tenía para direccionar el ordenamiento de la sociedad. La razón de este cuestionamiento tenía que ver con el debilitamiento del gobierno democrático y con el empobrecimiento que venían experimentando las poblaciones argentinas (Grimson, 2018). Estos fenómenos se venían dando, por lo menos, desde 1966 cuando Arturo Illia fue obligado a renunciar a la presidencia de Argentina por parte de quienes provocaron, en ese momento, un nuevo golpe cívico militar. El cuestionamiento de la eficacia del neoliberalismo permitió que el gobierno del estado fuera integrado por organizaciones políticas que privilegiaron el desarrollo humano de las poblaciones argentinas. Esto a través de la redistribución de lo que crea la sociedad entre sus poblaciones. En este contexto, las políticas para la formación ciudadana en la educación escolarizada se orientaron al ejercicio pleno e integral de la ciudadanía por parte de las niñas, de los niños y de las y los jóvenes. Postulo que esta situación tuvo 
que haberse desdibujado, entre 2015 y 2019, durante el gobierno de Mauricio Macri. La razón de esto es que este gobierno se orientó a la monopolización, por parte de unas pocas personas, de lo que crean todas las personas que integran la sociedad. En este sentido, queda como perspectiva de esta investigación conocer las características de la cultura política de las y los ciudadanos que se educaron a partir de 2001 desde la perspectiva del ejercicio pleno de los derechos por parte de las niñas, de los niños y de las y los jóvenes. Además, si esta perspectiva se desdibujó durante el gobierno de Macri y los efectos sociales que este cambio tuvo en caso de que se hubiese dado.

El segundo artículo fue escrito por las profesoras Eliana Bran Piedrahita, Natalia Godoy-Toro y Yuliana Monsalve Ruiz. Se titula "Perspectivas conceptuales y experienciales de la educación política: una mirada desde el grupo 'Educar para la Polis'”. Esta investigación se realizó en Colombia y desde la perspectiva de la formación ciudadana para la democracia. En ella participaron profesoras y profesores de educación básica y media. El objetivo de la investigación consistió en describir algunas de las experiencias de un grupo de profesoras y profesores que hacen parte del grupo "Educar para la Polis". Un grupo de trabajo académico en el campo de la educación política conformado por docentes de la educación escolarizada y no escolarizada colombiana. La descripción de estas experiencias tuvo como finalidad identificar algunas de las concepciones que este profesorado ha construido sobre la educación política a partir de sus prácticas educativas. En este sentido se les preguntó por las finalidades, los contenidos, los métodos de enseñanza y los procedimientos de los que se sirven para la evaluación de los aprendizajes del estudiantado. El horizonte de este artículo, elaborado por tres profesoras en ejercicio, es el de contribuir, desde el campo educativo, a la construcción de una convivencia democrática en el contexto colombiano. La base de esta investigación fue la conceptualización de la educación política y la presentación de tres perspectivas desde las que se ha desarrollado en las sociedades occidentales desde el siglo XIX. Estas son la instrucción cívica, la educación cívica y la formación ciudadana. El método de investigación utilizado por las profesoras fue el estudio de caso.

Desde la perspectiva de la formación ciudadana para la democracia, las y los estudiantes, se han de formar como agentes que gocen de tres características. La primera es que sean responsables de sus actuaciones; la segunda es que se interesen por la vida de quienes hacen parte de su comunidad política y la tercera es que desarrollen las capacidades para expresar juicios críticos y pensar en el bien común. Lo que permite humanizar la alteridad política y reconocerla como un fin en sí misma y no como un medio para obtener beneficios propios a través de su manipulación. Para cumplir con la finalidad anterior, los contenidos deben ser construidos por el profesorado. Pero no de manera 
solitaria sino de manera colectiva. Por esto, la construcción de los contenidos debe realizarse en el contexto de grupos de trabajo académico en los que el profesorado problematice y conceptualice diferentes situaciones sociales que sean de interés educativo. Los métodos de enseñanza de estos contenidos construidos por el profesorado deben poner en diálogo la teoría con la práctica. Además, deben propiciar la argumentación, el análisis, la reflexión y la proposición. Por lo que en el artículo se valora el método de problematización conceptualización propuesto por Isabelino Siede (2007).

Esta investigación deja dos perspectivas de investigación. La primera es el conocimiento de las prácticas educativas del profesorado con el que se realizó la investigación. La segunda es el conocimiento de las concepciones del estudiantado acerca de las prácticas educativas del profesorado. Estas dos perspectivas de investigación permitirían contrastar las concepciones del profesorado acerca de sus prácticas educativas con dos tipos de resultados. El primero sería el de las prácticas educativas que puedan ser observadas de este profesorado. El segundo sería el de las concepciones del estudiantado acerca de la prácticas de este profesorado. De esta manera, el conocimiento de las concepciones del profesorado acerca de sus prácticas educativas contrastado con el conocimiento de estas prácticas a través de su observación y con el de las concepciones del estudiantado acerca de las prácticas observadas permitiría definir propuestas que ayuden a cualificar los procesos de formación ciudadana del estudiantado para que aporte en los procesos que conlleven la democratización de su sociedad.

El tercer artículo, también corresponde a una investigación realizada en Colombia, fue presentado por la profesora Margarita Benjumea Pérez y por el profesor Alejandro Mesa Arango. Fue titulado "Educación y formación para la ciudadanía en y desde la universidad: aportes para el debate". Corresponde a una investigación que aborda la educación política desde la perspectiva de la formación ciudadana. Esta fue realizada con estudiantes de educación superior. El objetivo de la investigación, de la que se da cuenta en el artículo, fue el de identificar, visualizar y comprender, en primer lugar, algunas de las situaciones que se configuran en un contexto educativo del nivel superior con respecto a la formación ciudadana. Y, en segundo lugar, algunos de los dispositivos formativos que se despliegan en este mismo contexto educativo relativos, igualmente, a la formación ciudadana. El horizonte de esta investigación fue el de motivar procesos de reflexión y de acción con respecto a la formación ciudadana en la educación superior. El método mediante el que se realizó la investigación fue el de la investigación acción.

Desde la perspectiva de la formación ciudadana en el artículo se propone que la educación política debería orientarse a cumplir con dos finalidades. La primera sería la del desarrollo de las capacidades humanas del estudiantado desde la óptica de la 
autorrealización del sujeto. La segunda sería la de posibilitar la expresión del estudiantado mediante el sentimiento, la experiencia, la emoción y la motivación. Estas expresiones deberían desarrollarse desde una ética individual y colectiva. Además, deben relacionarse con la responsabilidad y la corresponsabilidad con sigo mismo, con los demás y con los entornos. Lo que deviene de una articulación ética de la construcción del conocimiento con la realidad del sujeto. Realidad que conjuga: el sentir, el querer, el hacer, el pensar, el actuar y el crear. Para el cumplimiento de estas finalidades se reconoce que los contenidos son de carácter no formal. Lo que significa que van más allá de los que están prescritos en el currículo. Esto porque la formación ciudadana en la educación superior "se va dando" en los encuentros de las y los estudiantes en torno a las múltiples temáticas que van emergiendo en la comunidad educativa. Por esto, los contenidos "van siendo" los asuntos que van tomando relevancia y que, por esto, van haciendo parte de las discusiones que se van dando en los diversos "espacios de aparición" que va creando la comunidad educativa. De esta forma, en la formación ciudadana en la educación superior es posible diferenciar unos "contenidos prescritos" y unos "contenidos no prescritos". En el artículo se postula que estos contenidos pueden cobrar más relevancia que los primeros. La razón de esto es que los "contenidos no prescritos" son los que, finalmente, llegan a ser los contenidos de los procesos de formación ciudadana en la educación superior. Teniendo en cuenta este carácter no prescrito de los contenidos de la formación ciudadana en la educación superior, los métodos de esta formación son, igualmente, no prescritos. Desde este aserto, en el artículo se propone que estos métodos promuevan escenarios de encuentros para que se articulen disertaciones, debates y deliberaciones. De una manera tal que un método de formación ciudadana en la educación superior debe pasar por la construcción de espacios de interacción con "el otro, los otros y con lo otro".

En la medida en que se ha visibilizado que los procesos de formación ciudadana en la educación superior se van dando en las discusiones que se van configurando en los diversos espacios de aparición que se van creando en la comunidad educativa se torna importante investigar dos aspectos. En primer lugar, las finalidades que, en estos procesos, se van configurando. Y, en segundo lugar, los contenidos y los métodos que, como se ha expresado, son no prescritos. La importancia que estos dos aspectos estriba es que en la educación superior se forman las y los profesionales que durante su paso por la educación superior y, luego, durante su ejercicio profesional tendrán una especial influencia en el devenir social. Esto porque sus conocimientos y sus saberes cobran una importancia especial en el devenir de la sociedad.

El cuarto artículo se refiere a una investigación realizada por las profesoras Ana María Calderón Jaramillo y Montserrat Oller Freixa. El artículo fue titulado "Temas 
controversiales y subjetividad política: una propuesta de educación política para jóvenes". La investigación fue desarrollada en Chile y aborda la educación política desde la perspectiva de la configuración de la subjetividad política. Esta investigación fue realizada con estudiantes, profesoras y profesores de educación superior. Tenía como objetivo comprender algunas de las maneras que configuran estudiantes de la educación superior para aprender a analizar su contexto, el de la sociedad chilena y para configurar sus subjetividades políticas. Esto a través de la controversia que genera el proceso de análisis de esta sociedad. A partir de esta comprensión, se buscó elaborar una propuesta de educación política de la que al final del artículo se presentan algunas ideas generales. El método que se utilizó para realizar la investigación fue el estudio de caso.

De acuerdo con esta investigación, la educación política a través de la configuración de la subjetividad política tiene dos finalidades. La primera consiste en cualificar la capacidad del estudiantado para analizar y reflexionar sobre su entorno social y su papel en este lugar de la sociedad. La segunda consiste en la elaboración de opiniones políticas por parte del estudiantado. Estas finalidades se fundamentan en que es importante pensar la educación política desde la subjetividad política. La razón de esto es que esta subjetividad está vinculada con el cuestionamiento que pueden hacer las personas de su entorno social y con el papel que pueden jugar en los procesos que permiten su transformación. Para cumplir con estas finalidades el profesorado ha de identificar temas que generan controversias en la sociedad de la que hace parte el estudiantado. Algunos de estos temas pueden ser la clonación; la inteligencia artificial; la radicalización de algunas de las personas que son adeptas a una religión; el suicidio de las personas jóvenes; la globalización y la participación política. El método de enseñanza de los temas que generan controversias en la sociedad de la que hace parte el estudiantado debe permitir darle un lugar privilegiado a las emociones del estudiantado. Lo que se basa en que la realidad es una imagen que, de suyo, provoca emociones. El privilegio de estas emociones ha de permitir que elabore opiniones políticas. Lo que se puede hacer logrando que cada estudiante reconozca si ha tenido contactos previos con los temas que se han traído a las aulas. En suma, se trata de incorporar la realidad de la sociedad en el aula y provocar emociones a fin de que el profesorado propicie que el estudiantado desarrolle un proceso de: indagación, reflexión, descripción y explicación. Todo esto orientado a que cada estudiante construya opiniones propias. En el desarrollo de este método se pueden utilizar herramientas como las fotografías u otro tipo de piezas gráficas relativas al tema abordado.

Este artículo deja como perspectiva de investigación el desarrollo de procesos de sistematización de experiencias que, de manera situada, den cuenta de las maneras en las que el profesorado puede lograr que en el abordaje de temas controversiales en el aula cada 
estudiante pueda pasar de la emoción a la opinión. En otras palabras, se trata de conocer las maneras en las que la provocación de emociones en las y los estudiantes no desemboca en resultados indeseados o no esperados como los que ocasionan las emociones cuando se desbordan. Esto si se entienden las emociones como aquellas alteraciones intensas y momentáneas del ánimo, de la actitud, de la postura o de la disposición de las personas.

El quinto artículo fue escrito por la profesora Edda Sant. Lo tituló "Educación política para una democracia radical". En el artículo se desarrollan una serie de reflexiones en torno a la educación política que se orienta a educar al estudiantado para que contribuya al desarrollo de una democracia radical. Estas reflexiones se fundamentan en algunas investigaciones realizadas por la autora en el contexto español. Estas investigaciones fueron realizadas con estudiantes de la educación primaria y secundaria. El método de realización de esta síntesis fue el de la revisión documental. A partir de estas investigaciones en el artículo se propone una finalidad para los procesos de educación política. Esta es la de formar al estudiantado para que aporte en los procesos que permitan construir una democracia radical. Una concepción de los ordenamientos democráticos construida por Ernesto Laclau y Chantal Mouffe. Vale la pena anotar que, esta finalidad como todas las otras que pueda cobrar la educación política, corresponde a las intencionalidades de los procesos educativos. Por esto, la educación política no se puede reducir a una área o a una asignatura concreta. Pero sí, se debe desarrollar, de una manera enfática, en campos como los de la educación para la ciudadanía, las ciencias sociales, la historia, la geografía y la filosofía. En concordancia con esta finalidad, cuando el profesorado desarrolla procesos de educación política para formar al estudiantado para que aporte en los procesos que permiten construir un orden democrático radical ha de servirse de contenidos que deben ser construidos por el profesorado y por el estudiantado a través de actividades de indagación. En estas actividades pueden elaborar preguntas a las que han de buscar darle respuestas, consultando fuentes primarias y secundarias. Por ejemplo, pueden acopiar textos que hagan parte del campo de las ciencias sociales o pueden averiguar la opinión de personas pertenecientes a sus entornos. En general, tanto el profesorado como el estudiantado, pueden acudir a los conocimientos que se han construido en el campo de las ciencias sociales y, además, a aquellos conocimientos y saberes que circulan de diversas maneras en la sociedad.

Para ejemplificar un proceso de educación política que forme al estudiantado para que aporte en aquellos procesos que permitan construir una democracia radical, en el artículo, se describen algunos aspectos de la manera en la que se podría desarrollar un trabajo de educación para la ciudadanía global. En principio se resalta que la función del profesorado es la de facilitar tanto la participación como los cambios del estudiantado. 
Con respecto a esta función se advierte que el profesorado debe velar por que la dirección de estos cambios quede en manos del estudiantado. Sin embargo, el profesorado debe procurar que estos cambios no sean contrarios a la ética o al conjunto de valores que, para cada profesor o profesora, deben regir el transcurso político. Aclarada la función del profesorado se puede postular que el método contenido en el artículo debería componerse de tres momentos: el primero sería el de la definición de una conceptualización; el segundo sería el de el posicionamiento en una conceptualización y, el tercero, sería el de la conexión con personas afines a la conceptualización en la que se posicionó cada estudiante. Esto a fin de que este posicionamiento pueda definirse como hegemónico. En el curso de estos momentos la definición de una conceptualización puede realizarla el estudiantado consultando referentes teóricos del campo de las ciencias sociales; aplicando cuestionarios entre las personas de sus entornos o consultando los resultados de encuestas o las opiniones que pueden ser expresadas y difundidas a través de diversos medios de comunicación. El posicionamiento en una conceptualización puede realizarla el estudiantado estableciendo diálogos con personas de diversos contextos y la conexión con personas afines a la conceptualización en la que se posicionó cada estudiante puede ser instaurada mediante el acercamiento a organizaciones que propugnan por definir como hegemónica la conceptualización en la que se posicionó cada estudiante.

Este artículo deja dos perspectivas de investigación. La primera es la de conocer las maneras en las que el profesorado puede facilitar que el estudiantado tome el control de sus cambios sin que, estos, sean contrarios a las éticas que permiten la dignificación de la condición humana. La segunda es la de conocer las formas en las que el profesorado puede acompañar al estudiantado en la creación de conexiones con personas y organizaciones que busquen definir como hegemónica la conceptualización en la que se puede posicionar cada estudiante en el transcurso de un proceso de educación política que permita construir una democracia radical.

El sexto artículo fue escrito por los profesores Salvador Sala, Antoni Santisteban-Fernández y Joan Pagès. Fue titulado "Una investigación sobre el desarrollo del currículo de educación para una ciudadanía democrática en la escuela andorrana”. Como se puede observar en este título la investigación fue realizada en el principado de Andorra. La perspectiva desde la que se abordó la educación política fue la del desarrollo de competencias en el campo de la educación para la ciudadanía democrática. El artículo presenta algunos resultados de una investigación realizada con profesoras, profesores y estudiantes de la educación secundaria. Fue realizada desde la teoría de la educación basada en competencias (Butova, 2015). Un tipo de educación que se desarrolló a partir de algunas de las investigaciones realizadas por Raven (1988a; 1988b). Por lo que tuvo 
como objetivo conocer las perspectivas didácticas y las razones que mueven al profesorado de ciencias sociales para llevar a la práctica un currículo que permita que el estudiantado desarrolle competencias en el campo de la educación para la ciudadanía democrática. El método al que se acudió para realizar la investigación fue el estudio de caso en el que se utilizó como técnica de análisis de los datos la teoría fundamentada.

La finalidad de desarrollar competencias para ejercer una ciudadanía democrática consiste en que cada estudiante disponga de unos conocimientos y unas habilidades para que construya decisiones, reivindique sus derechos e intervenga en su contexto cercano. De manera especial, en lo que respecta a las decisiones, en el artículo se precisa que, estas, deben poder ser argumentadas por cada estudiante y ser coherentes con los problemas que el estudiantado debe comprender y enfrentar, de una manera crítica, en el día a día. En el artículo se propone como contenido de una educación que permita el desarrollo de competencias para el ejercicio de una ciudadanía democrática para abordar problemas sociales que sean relevantes en el contexto del estudiantado. Por ejemplo, en el entorno andorrano un problema social relevante es el fenómeno de las migraciones. Para abordar en el aula problemas sociales que resulten relevantes en el entorno del estudiantado en el artículo se proponen dos actividades. La primera consiste en la presentación del problema social relevante por parte de la profesora o del profesor y la segunda consiste en la realización de cuatro tareas por parte del estudiantado. Estas tareas deben ser llevadas a cabo en un primer momento de manera individual y en un segundo momento de manera colectiva. La primera tarea es la descripción del problema; la segunda es el análisis de los argumentos referidos a los problemas que circulan en la sociedad y que, por supuesto, puedan ser acopiados por el estudiantado; la tercera es la elaboración de argumentos propios y la última es la proposición de una solución al problema social relevante abordado. Para realizar estas tareas el estudiantado puede consultar artículos de prensa, resultados de encuestas de opinión, códigos éticos como la Declaración Universal de los Derechos Humanos de 1948, códigos normativos como las constituciones políticas e informes de entidades de los gobiernos de los estados o de organizaciones no gubernamentales. Vale anotar que la identificación de los argumentos que circulan en la sociedad con relación al problema social relevante debería ser una tarea que se puede deslindar de las anteriores. Esto por la importancia que cobra en los procesos de educación política las tareas de construcción de la información que en un contexto educativo dialógico puede tornarse en conocimientos y saberes que han de orientar el sentido de las prácticas del estudiantado en su vida cotidiana.

Este artículo deja como perspectiva de investigación el conocimiento de las maneras en las que el profesorado puede acompañar al estudiantado para que desarrolle los procesos 
cognitivos que implican el abordar problemas sociales relevantes. De acuerdo con el artículo estos procesos son: la descripción del problema; la identificación de los argumentos que circulan en la sociedad referidos al problema; el análisis de estos argumentos; la elaboración de argumentos propios y la proposición de soluciones al problema abordado.

El último artículo, corresponde al ámbito de la educación no escolarizada. Fue escrito por las investigadoras Tiffany Andrea Botero y Luisa María López. Fue titulado "Reflexiones sobre la implementación del Sistema de Formación para la Participación Ciudadana en Medellín 2017-2019”. La investigación en la que se argumenta fue realizada en Colombia con personas jóvenes y adultas. La perspectiva desde la que se abordó la educación política fue la de formación para la participación ciudadana. En este artículo, se presentan algunos de los resultados de la sistematización de un proceso de formación de personas jóvenes y adultas para la participación ciudadana. Este proceso tuvo tres características que es menester mencionar: la primera es que fue orientado por profesoras y profesores adscritos a una universidad pública, la Universidad Nacional de Colombia; la segunda es que se realizó en cumplimiento de un contrato con una de las instituciones de un gobierno local -la Alcaldía de Medellín- y la tercera es que se realizó entre los años 2017 y 2019 con distintos grupos de personas. Algunos grupos estuvieron integrados por jóvenes y otros por personas adultas. Finalmente, como se ha mencionado, el artículo presenta los resultados de una sistematización de estos procesos educativos. Esta se realizó a partir de relatos que, desde lo subjetivo, dieran cuenta de la experiencia construida a lo largo del proceso por sus participantes.

Desde la perspectiva de la formación para la participación ciudadana, en el artículo se sostiene que la finalidad de la educación política es formar a las personas para participar en el campo político. Lo que puede hacerse mediante el fortalecimiento de sus capacidades para que contribuyan a construir una democracia participativa. Este fortalecimiento puede fundamentarse en dos teorías: la de las capacidades humanas que ha sido configurada por Amartya Sen y por Martha Nussbaum y la del desarrollo humano. La fundamentación en estas teorías permitió que durante el proceso formativo se enfatizara en la importancia de ampliar las oportunidades de las personas para que fortalezcan sus capacidades. Lo que puede hacerse mediante los procesos educativos. Por esto, las capacidades que buscó fortalecer el profesorado que orientó el proceso de formación para la participación ciudadana fueron las de imaginar, elaborar juicios críticos, controlar el entorno próximo, devenir desde una praxis ética y vivir con y para las demás personas. Para cumplir con esta finalidad los contenidos seleccionados para este proceso de formación para la participación ciudadana fueron concertados entre las personas que hicieron parte del mismo. Por esto, cambiaron cada vez que se terminó de 
desarrollar el proceso formativo con un grupo de personas y se inició con otro. Algunos de los contenidos abordados fueron los siguientes: la perspectiva de actuación desde los derechos; elementos de derecho constitucional; formación territorial; economía política; valores comunitarios y paz territorial. Finalmente, ha de anotarse que resultó importante durante el proceso de formación un contenido emergente. Este fue el de la enseñanza de elementos de investigación para el conocimiento de las sociedades. Este contenido, además, pasó a hacer parte del método de formación para la participación ciudadana que se sistematizó y del que buscó dar cuenta el artículo.

El método de formación para la participación ciudadana que se utilizó durante el proceso de sistematización se fundamentó en algunos elementos tomados de tres teorías pedagógicas: la pedagogía crítica, la educación experiencial y la animación sociocultural. El elemento tomado de la pedagogía crítica proviene de Paulo Freire. En especial, su concepción de que los procesos educativos deben propiciar la libertad de las personas. Por lo mismo, estos procesos deben contribuir a que pierdan el miedo a ejercer su libertad. Una idea que fue cualificada por Freire a partir de su lectura de Erich Fromm (2008). De esta manera, mediante la educación, las personas pueden lograr emancipar su subjetividad de los entramados de signos y de símbolos con los que algunas y algunos buscan dominarlas. El elemento tomado de la educación experiencial consiste en que, durante el proceso educativo, las educadoras y los educadores deben procurar que las personas construyan conocimientos a partir de la experiencia. Finalmente, el elemento tomado de la animación sociocultural consiste en que la construcción de conocimientos debe realizarse a partir de la participación. Elemento que se basa, a su vez, en uno de los principios de la pedagogía crítica freireana el cual es que la educación no es un proceso de transmisión de conocimientos. Es un proceso en el que se construyen conocimientos de forma colectiva entre quienes enseñan aprendiendo y quienes aprenden enseñando. Por esto, a la educación le es inherente la participación. Con lo que quedan claros los fundamentos freireanos de la animación sociocultural. Estas teorías pedagógicas se concretaron en el proceso de formación en tres criterios metódicos. El primero, fue el reconocimiento de los saberes y de los conocimientos de las personas que hicieron parte de los procesos de formación. El segundo, fue el uso de procedimientos en los que se buscaba la participación y la interacción de estas personas. El tercero, fue el de propiciar la investigación del contexto social por parte de las mismas. Lo que fue un elemento que les permitió expandir sus capacidades para conocer sus entornos. Como se anotó, la investigación fue tanto un contenido como un método. De esta forma, los procesos de formación incluyeron las siguientes actividades: recuperación de saberes, profundización teórica, reflexión y valoración de estas actividades a fin de cualificarlas a medida que avanzaba el proceso de formación. 
Este artículo deja como perspectiva investigar los efectos que, en un proceso de formación para la participación ciudadana, tiene la circunstancia de que la iniciativa del proceso formativo sea de una entidad estatal. Desde esta perspectiva, las autoras mostraron que las teorías pedagógicas que orientaron el método de formación de las personas jóvenes y adultas para la participación ciudadana tuvieron que ser matizadas. Los resultados de esta perspectiva de investigación pueden resultar interesantes si se contrastan con una de las deontologías de las prácticas educativas. Esta consiste en que la función del profesorado debe ser de carácter intelectual. Por tanto, en un proceso de formación para la participación ciudadana el profesorado debe construir de manera autónoma y, en el contexto de grupos de trabajo académico docente, las finalidades, los contenidos, los métodos y las formas de evaluación de los aprendizajes. Esto es importante si se tiene en cuenta que la educación debería entenderse como una "práctica de la libertad" (Freire, 2009).

Como se ha manifestado, en los anteriores artículos se presentan algunos de los resultados de diversas investigaciones realizadas en el campo de la educación política. A continuación, el presente monográfico, contiene tres textos que se refieren a este mismo campo. Estos son una reseña; una entrevista y una semblanza académica de un maestro de maestros: el profesor Joan Pagès i Blanch, quien nos dejó el 3 de junio de 2020, después de haber dedicado su vida a cualificar el campo de la educación política.

La reseña fue escrita por el profesor Edwin Fabián Bustamante Arango. Fue titulada "Educación política para la construcción de sociedades democráticas". En esta se examina el libro "Educación política en una democracia" de Harold Entwistle (1923-2015). Esta reseña resultó ser de interés para el monográfico por dos razones. La primera tuvo que ver con que Entwistle comenzó su desarrollo profesional docente como maestro de escuela primaria y secundaria. Después lo prosiguió como maestro de una escuela normal y de otra de adultos. Unos años más tarde lo continuó como maestro de universidad en el Reino Unido y en Canadá. La segunda razón tuvo que ver con que este devenir profesional le permitió fundamentar una teoría en torno a la educación política que se centra en la democratización de las sociedades. Por estas dos razones esta reseña es la de un libro de un profesor que teorizó sobre sus prácticas desde el horizonte del ordenamiento democrático. Por lo escrito, este libro cobra interés para las y los educadores políticos. Aún más si se considera la ventaja que, en la actualidad, ha ganado la autocratización de muchas de las sociedades del planeta. Una ventaja que se aceleró durante la crisis económica que se inició a finales de 2007 en el sector inmobiliario estadounidense y que se avivó con la crisis de salud planetaria que se evidenció en el último tramo de 2019. Crisis que se puede atribuir a los tres fenómenos que, reforzándose mutuamente, sostienen el ordenamiento capitalista: la reificación, la autocratización 
y la monopolización. De esta manera, la autocratización que viene cobrando fuerza en el momento presente resulta ser el efecto y además la causa de la manera indigna en la que vive la mayoría de la población del planeta. Por lo que en la contemporaneidad resulta imprescindible la educación política. Pero no cualquier educación política. La que resulta trascendente es aquella que permita la democratización de las sociedades.

Por las razones anotadas, el profesor Edwin Bustamante reseñó un libro que está circulando hace cincuenta años. Esto porque fue publicado, originalmente, en inglés en 1971 y dado a conocer en el ámbito hispanófono en 1980. Por otra parte, se ha escrito que en esta reseña se examina este libro. Con esto se quiere decir que no consiste en una mera descripción de su contenido. Es una interpretación desde el punto de fuga de un maestro que se dedica a reflexionar sobre su práctica. De este modo, la reseña contiene en un primer aparte un concepto de educación política y algunos de sus fundamentos. En un segundo aparte expone una relación entre la democracia, la educación política y los currículos. Lo que lleva a que en el aparte de cierre se consignen algunas ideas sugerentes relativas a la educación política en el contexto colombiano. Ideas sobre las cuales sería importante seguir discutiendo en el contexto de las agrupaciones académicas centradas en la educación política.

La entrevista fue realizada al profesor Isabelino Siede por quien edita este monográfico, por el profesor Juan Esteban Clavijo y por las profesoras Natalia Godoy-Toro y Marta Restrepo. El interés por incluir esta entrevista deviene de la condición de Siede de profesor de la educación primaria y de la educación superior. En la educación primaria se ha dedicado a la formación del estudiantado a través del conocimiento de las sociedades. Y, en la educación superior se ha concentrado en formar profesoras y profesores de ciencias sociales. Estas labores las ha desarrollado con un especial énfasis desde la educación política y a partir de la reflexión sobre sus prácticas educativas. Una reflexión que ha sido comunicada por este profesor en numerosas publicaciones que han tenido amplia circulación en Argentina y en el ámbito hispanoamericano. Esta entrevista comienza con el transcurrir personal y académico del profesor Siede desde su propia voz. Un transcurso que, como en todas las personas, está hilvanado. Prosigue con su concepción de la Educación Política y de sus relaciones con la democracia y la emancipación personal y colectiva. Se detiene en las singularidades de la Educación Política en el contexto latinoamericano. Una particularidad que tiene que ver con la biodiversidad y la pluriculturalidad de este recodo del universo. Llegando al final, se trazan algunas ideas en torno a la educación política durante las pandemias. Lo que se puede entender si se tiene la conciencia de que la actual pandemia - Covid-19- está inscrita en la historia del ordenamiento capitalista. Por lo que no es la primera, ni será la última. Y qué por esto las pandemias cesarán cuando 
dejemos atrás el ordenamiento capitalista que ocasiona este tipo de afecciones que nos dejan en la perplejidad. La entrevista se cierra con unas reflexiones en torno a la educación política, el deleznable adoctrinamiento y la consistente politización. Reflexiones que abren la perspectiva de pensar en los modos de preservar la integridad física y psíquica de aquellas profesoras y profesores dedicadas a la politización del estudiantado a través de una educación política que apunte a democratizar su sociedad.

El monográfico se cierra con la semblanza académica del profesor Joan Pagès. Un texto escrito por el profesor Antoni Santisteban-Fernández titulado "Las contribuciones de Joan Pagès a la educación política: una obra imprescindible”. Para la edición de este monográfico la inclusión de este escrito ha sido especialmente gratificante. Quizás porque el profesor Santisteban-Fernández tuvo la fortuna de hacer parte de uno de sus tantos grupos de estudiantes y, luego, ser uno de sus colegas y amigos más cercanos. Desde este lugar excepcional, este escrito muestra algunos de los muchos aportes que el profesor Pagès realizó en el campo de la educación política.

A mi juicio, uno de los más trascendentes, es la concepción de que la educación política debe ser democrática. Esto a fin de que cada estudiante pueda, desde el ejercicio de la condición ciudadana, participar en los procesos que contribuyan a democratizar su sociedad. Sobre esta valiosa concepción puede mencionarse, en primera instancia, que fue construida por el profesor Pagès, de manera inicial, en la década de los años setenta del siglo XX, en el contexto de un grupo académico de docentes, la Associació de Mestres Rosa Sensat; la continuó en las "aules" de la Universitat Autònoma de Barcelona y viene germinando, de manera especial, en las aulas de diversas instituciones educativas de Nuestra América. Lo que permite escribir que la labor de educador político del profesor Pagès se inició en medio de la violencia ejercida por la dictadura de una elite fascista contra las poblaciones españolas. Y, luego, esta labor, prosigue en una Iberoamérica en la que miles de personas y de organizaciones procuran que sus días estén consagrados a la construcción de un ordenamiento democrático. En segunda instancia, la concepción de educación política del profesor Pagès enfatiza en que el estudiantado se debe formar para que aprenda a construir consensos de manera pacífica. Por esto, va más allá de la enseñanza de contenidos. Tiene que ver con los métodos de enseñanza y de aprendizaje de estos contenidos. De aquí que la educación política tenga que ser democrática. Lo que tiene como base la formación del profesorado de historia, de geografía, de ciencias sociales, de economía o de cualquier otro campo del saber o del conocimiento desde la perspectiva crítica. Aquel punto de fuga desde el que es posible dignificar la condición humana. Por esta enseñanza y por muchas otras que son inconmensurables este monográfico está dedicado al profesor Pagès. Un maestro de maestros que nos ha dejado en la 
memoria su aprecio por las aulas. Unos espacios para el encuentro del profesorado con el estudiantado que fueron para él lugares para pensar, para luchar y para amar. Quizá por esta razón se sentía su emoción cuando le daba inicio a sus clases con uno de los entrañables versos del poeta de Nuestra América Amado Nervo:

“¡Aquí se piensa, Aquí también se lucha, ¡Aquí se ama!”. Éxtasis, 1915

\section{Referencias}

[1] BBC Mundo. (2017, 15 de junio). La tumultuosa historia de los Al Thani, la poderosa y multimillonaria familia que rige Qatar. https://bbc.in/3x2UOLE

[2] Bobbio, N. (2009). Democracia: los fundamentos. En M. Bovero (ed.), Teoría general de la política (pp. 401-417). Trotta.

[3] Botero, P. (2014). Comunidades en reexistencia: rutas y ampliación del significado de la democracia [presentación de ponencia]. VIII Coloquio Colombiano de Investigadoras e Investigadores en Formación Ciudadana, Universidad de Manizales, Colombia.

[4] Bourdieu, P. (1988). La distinción, criterio y bases sociales del gusto. Taurus.

[5] Butova, Y. (2015). The History of Development of Competency-based Education. European Scientific Journal, 1, 250-255.

[6] Dussel, E. (2013). 16 tesis de economía política. Una filosofía de la economía. Docencia.

[7] Calderón, C., Romero, F. y Gómez, L. (1995). Salud ambiental y desarrollo. Ecosolar.

[8] Entwistle, H. (1980). La educación política en una democracia. Narcea.

[9] Freire, P. (2009). La educación como práctica de la libertad. Siglo XXI.

[10] Fromm, E. (2008). El miedo a la libertad. Paidós.

[11] Grimson, A. (2018). Argentina y sus crisis. Nueva Sociedad, 273. https://bit.ly/3tIGKc1

[12] Henao, B., y Palacio, L. (2019). Formación científica civilista: un propósito inaplazable para la educación en Ciencias Naturales. Revista Educación y Pedagogía, 27(69/70), 100106. https://revistas.udea.edu.co/index.php/revistaeyp/article/view/340208

[13] Hobsbawm, E. (1995). Historia del siglo XX: 1914-1991. Crítica.

[14] Honneth, A. (2007). Reificación: un estudio en la teoría del reconocimiento. Katz.

[15] Human Rights Watch dice que tanquetas de la Policía con proyectiles son "peligrosas" e "indiscriminadas". (2021, 6 de mayo). El Espectador. https://bit.ly/3u3DFn2 
[16] Indepaz [@Indepaz]. (2021, 18 de mayo). Hechos de violencia en el marco del paro nacional [Tuit]. Twitter. https://bit.ly/3yoJ1wL

[17] Larrosa, J. (2006). Sobre la experiencia. Separata Revista Educación y Pedagogía, 18, 43-67.

[18] Lechner, N. (1981). Especificando la política [presentación de Ponencia]. Taller sobre estado y política en América Latina del Departamento de Estudios Políticos del CIDE, México. https://bit.ly/3787P0k

[19] Linares, V. (2021, 24 de febrero). The Guardian: 6.500 trabajadores murieron en las obras del Mundial 2022 en Qatar. Radio Francia Internacional. https://bit.ly/2OY0jyQ

[20] López-Martínez, M. (2004). Noviolencia para generar cambios sociales. Polis. Revista Latinoamericana, 9, 1-19. https://journals.openedition.org/polis/7326

[21] Max-Neef, M., Elizalde, A. y Openhayn, M. (1996). Desarrollo a escala humana: una opción para el futuro. Proyecto 20.

[22] Marshall, T. (1997). Ciudadanía y clase social. REIS, Revista Española de Investigaciones Sociológicas, 79, 297-344.

[23] Mauss, M. (2009). Ensayo sobre el don, forma y función del intercambio en las sociedades arcaicas. Katz.

[24] Mouffe, C. (2017). El retorno de lo político, comunidad, ciudadanía, pluralismo, democracia radical. Paidós.

[25] Pagès, J. (1997). Los conflictos en las sociedades rurales: el Conflicto Remensa s. XV y el Conflicto de Chiapas 1994. En P. Benejam y J. Pagès (coords.), Ciencias sociales contenidos, actividades y recursos guías Praxis para el profesorado de ESO (pp. 415-480). Praxis.

[26] Raven, J. (1988a). A Critique of Sternberg's and Gardner's Concept of Multiple Intelligences. http://www.eyeonsociety.co.uk/resources/acritiqueofsternbergs.pdf

[27] Raven, J. (1988b). Developing the Talents and Competencies of all Our Children. Gifted International, 5(1), 8-40. https://doi.org/10.1080/07387849.1988.11674822

[28] Sani, G. (2000). Participación política. En N. Bobbio, N. Matteucci y G. Pasquino (dirs.), Diccionario de Política (pp. 1137-1140). Siglo XXI.

[29] Santos, B. de S. (2009). Una epistemología del sur: la reinvención del conocimiento y de la emancipación social. Siglo XXI; Clacso.

[30] Santos, B. de S.. (2018). Izquierdas del mundo ¡uníos! Icaria.

[31] Saramago, J. (2010). Memorial del convento. Punto de Lectura.

[32] Sen, A. (2000). Desarrollo y libertad. Planeta.

[33] Siede, I. (2007). La educación política: ensayos sobre ética y ciudadanía en la escuela. Paidós.

[34] Temblores ONG [@TembloresOng]. (2021a, 10 de mayo). May 9 press reléase [Tuit]. Twitter. https://bit.ly/33YeVCj 
[35] Temblores ONG [@TembloresOng]. (2021b, 18 de mayo). \#Atención [Tuit]. Twitter. https://bit.ly/3ypfjb6

[36] Thiong'o, N. (2017). Desplazar el centro: la lucha por las libertades culturales. Rayo Verde.

[37] Thoreau, H. D. (2005). Del deber de la desobediencia civil. Universidad Nacional Autónoma de México.

[38] Tilly, C. (2004). ¿De dónde vienen los derechos? Sociológica, 19(55), 273-300. https:// www.redalyc.org/pdf/3050/305026635010.pdf

[39] Organización de las Naciones Unidas para la Educación, la Ciencia y la Cultura (Unesco). (2021). Real Obra de Mafra: palacio, basílica, convento, jardín del "Cerco" y parque de caza real de la Tapada. https://bit.ly/2ROWIEB

[40] Villa, M. E. (2011). Del concepto de juventud al de juventudes y al de lo juvenil. Revista Educación y Pedagogía, 23(60), 147-157.

[41] Villa, M. E.. (2015a). La enseñanza de conocimientos y saberes políticos en la escuela: un medio para la construcción de sociedades democráticas. Nuevas Dimensiones: Revista Electrónica de Didáctica de las Ciencias Sociales, 6, 91-124.

[42] Villa, M. E. (2015b). La docencia intelectual: una posibilidad para la reconstrucción del ámbito político. En D. Trejo y J. Martínez (coords.), La historia enseñada a discusión, retos epistemológicos y perspectivas didácticas (pp. 2121-2131). Morevalladolid.

[43] Villa, M. E. (2021a). Una tipología de los poderes sociales [manuscrito sin publicar].

[44] Villa, M. E. (2021b). El método DAR: un procedimiento para construir experiencias durante los procesos de Educación Política. [manuscrito sin publicar].

[45] Wilches-Chaux, G. (1993). El sentido de la participación. En P. Brand (ed.), Participación comunitaria: memorias tercer seminario internacional organizado por HABINET y realizado por CEHAP (pp. 1-12). Habinet; Cehap; Universidad Nacional de Colombia.

[46] Žižek, S. (2011). El espinoso sujeto: el centro ausente de la ontología política. Paidós. 